\title{
A hypothesis on chemical mechanism of the effect of hydrogen
}

\author{
Penghui Shi ${ }^{1,3^{*}}$, Wancang Sun ${ }^{1+}$ and Pengzhong Shi ${ }^{2}$
}

\begin{abstract}
Many studies have shown that hydrogen can play important roles on the antioxidant, anti-inflammatory and other protective effects. Ohsawa et al have proved that hydrogen can electively and directly scavenge hydroxyl radical. But this mechanism cannot explain more new experimental results. In this article, the hypothesis, which is inspired by $\mathrm{H}_{2}$ could bind to the metal as a ligand, come up to explain its extensive biology effect: Hydrogen could regulate particular metalloproteins by bonding $\left(\mathrm{M}-\mathrm{H}_{2}\right.$ interaction) it. And then it could affect the metabolization of ROS and signal transduction. Metalloproteins may be ones of the target molecules of $\mathrm{H}_{2}$ action. Metal ions may be appropriate role sites for $\mathrm{H}_{2}$ molecules. The hypothesis pointed out a new direction to clarify its mechanisms.
\end{abstract}

Keywords: Hypothesis, Hydrogen, Mechanism, Ligand

\section{Background}

Basal cellular metabolism continuously produces reactive oxygen species (ROS). $\mathrm{O}_{2}$ may generate successively superoxide $\left(\mathrm{O}_{2-}\right)$, hydrogen peroxide $\left(\mathrm{H}_{2} \mathrm{O}_{2}\right)$ and hydroxyl radical $(\mathrm{OH} \cdot)$. ROS are able to oxidize biological macromolecules such as DNA, protein and lipids [1,2]. Some enzymic systems detoxify ROS, however, catalase dismutates $\mathrm{H}_{2} \mathrm{O}_{2}$, and SOD eliminates $\mathrm{O}_{2-}$ (but generates $\mathrm{H}_{2} \mathrm{O}_{2}$ ). Excess oxygen can react with $\mathrm{H}_{2} \mathrm{O}_{2}$ to produce hydroxyl radicals by the Fenton reaction [3] (Figure 1). Ohsawa et al provide evidence that hydrogen could reach subcellular compartments such as the nucleus and mitochondria, biochemical experiments using fluorescent probes and electron paramagnetic resonance spectroscopy spin traps indicated that hydrogen gas may selectively scavenge the hydroxyl radical [4]; They were the first to show the ability of $\mathrm{H}_{2}$ to suppress oxidation in vivo. So far, many researches have proved the central role of hydrogen on the antioxidant, anti-inflammatory and other protective effects.

\footnotetext{
* Correspondence: shiph150@sina.cn

${ }^{\dagger}$ Equal contributors

'Gansu Key Lab of Crop Improvement \& Germplasm Enhancement, Gansu Provincial Key Laboratory of Aridland Crop Sciences, Gansu Agricultural University, Lanzhou 730070, China

${ }^{3}$ Gansu Agricultural University, Anning District, Lanzhou City, Gansu Province, China

Full list of author information is available at the end of the article
}

Much evidence has shown that hydrogen exert beneficial effects in animal models of a number of diseases mainly associated with oxidative stress; However, the findings don't cover plants. Moreover, the mechanism of the effect of hydrogen remains unclear, the most acceptable mechanism is that the hydrogen can electively and directly scavenge hydroxyl radical while preserving other reactive oxygen and nitrogen species important in signaling [4]. There is some question, however, the published rate constant for the reaction of $\mathrm{OH}$ with $\mathrm{H}_{2}$ to form $\mathrm{H}_{2} \mathrm{O}$ and $\mathrm{H}$. is drastically slower than most radical-radical reactions [6]. Furthermore, it can't explain some new experimental results. For example, Tomohiro Itoh proved that hydrogen exerts its beneficial effect by modulating some signaling pathways. Experimenters found that oral intake of hydrogen-rich water abolishes an immediate-type allergic reaction in mice. The results indicated that hydrogen attenuates phosphorylation of the FceRI-associated Lyn and its downstream signal transduction, which subsequently inhibits the NADPH oxidase activity and reduces the generation of hydrogen peroxide. they also found that inhibition of NADPH oxidase attenuates phosphorylation of Lyn in mast cells, indicating the presence of a feedforward loop that potentiates the allergic responses. Hydrogen accordingly inhibits all tested signaling molecule(s) in the loop. The results imply that effects of hydrogen in some diseases are possibly mediated by modulation of yet unidentified signaling pathways [7].

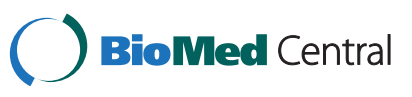

(c) 2012 Shi et al.; licensee BioMed Central Ltd. This is an Open Access article distributed under the terms of the Creative Commons Attribution License (http://creativecommons.org/licenses/by/2.0), which permits unrestricted use, distribution, and reproduction in any medium, provided the original work is properly cited. 


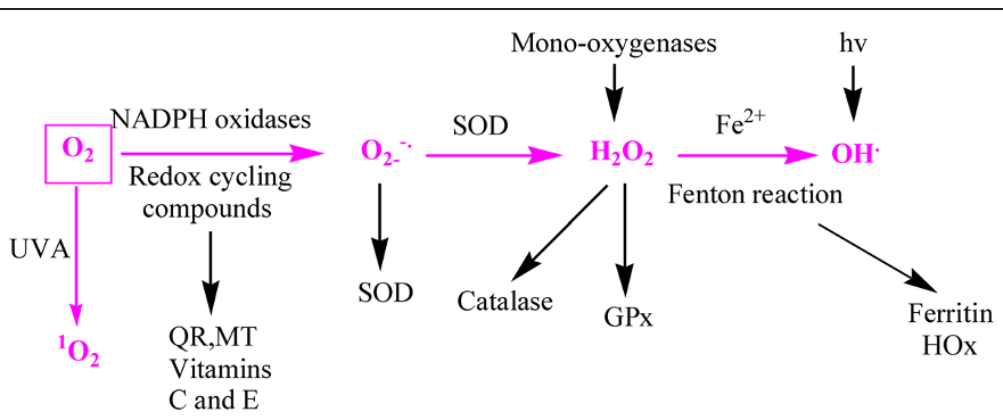

Figure 1 ROS generation and detoxification. Various chemical reactions, with or without enzymic catalysis, generate ROS. The dioxygen molecule undergoes successive reductions which yield the superoxide radical anion $\left(\mathrm{O}_{2-}\right)$, hydrogen peroxide $\left(\mathrm{H}_{2} \mathrm{O}_{2}\right)$ and the hydroxyl radical $(\mathrm{OH} \cdot)$. Antioxidant systems act as ROS scavengers to maintain the intracellular redox status. Quinone reductase (QR) detoxifies quinone compounds, metallothionein (MT) traps (heavy) metal cations, and vitamins C and E trap free radicals. SOD and catalase respectively dismutate superoxide (into oxygen and hydrogen peroxide) and hydrogen peroxide (into oxygen and water). Glutathione peroxidase (GPx) acts like catalase on various peroxide compounds, including $\mathrm{H}_{2} \mathrm{O}_{2}$ [5].

\section{Hypothesis and discussion}

Although the beneficial effect of hydrogen is generally accepted, the mechanism is not still clear. There can be little doubt that biology function of $\mathrm{H}_{2}$ depends on the physical and chemical interaction of other molecules with it, so what would it be like?

In organometallic and inorganic chemistry, for some metal complexes, the "arrested" addition product can be isolated-the dihydrogen complex is obtained as a stable species that can be put in a bottle: [8] (Scheme 1).

Traditional ligands use lone pairs of electrons in their bonding, but in dihydrogen complexes, the bonding to the metal comes from donation of electron density from the nonpolar $\mathrm{H}-\mathrm{H} \sigma$ bond to d orbitals on the metal (Figure 2). We hold that hydrogenase is a typical case in point. Hydrogenases catalyse the reversible oxidation of molecular hydrogen $\left(\mathrm{H}_{2}\right)$. The active site domain of the Fe hydrogenases contains an unusual Fe-S centre termed the $\mathrm{H}$-cluster. $\mathrm{H}$-cluster consists of the $\left[\mathrm{Fe}_{4} \mathrm{~S}_{4}\right]$ subcluster bridged via the Cys thiolate to the $\left[\mathrm{Fe}_{2}\right]$ (binuclear iron) subcluster (Figure 3) [9-12]. Iron sulfur clusters are found at the active sites of numerous enzymes where they commonly facilitate electron transfer and substrate transformations (Table 1) [13]. It is infered that $\mathrm{M}-\mathrm{H}_{2}$ interaction also exists in these metalloproteins. By extension, it also should exist in non-cluster metalloproteins. All this suggestes that metal ions may be the site where $\mathrm{H}_{2}$ interacted with metalloproteins.

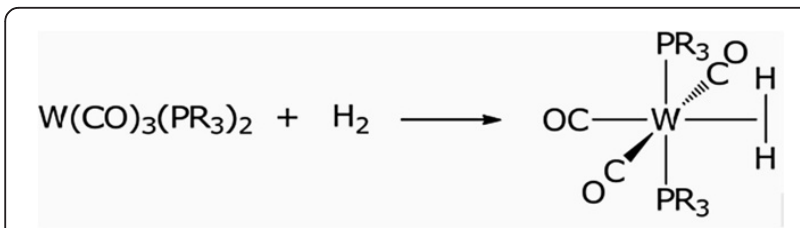

Scheme 1 Formation of a dihydrogen complex.
It is proved from experiments that molecules containing a metallic cation may promote $\mathrm{O}_{2-}$ formation because they have the ability to store and easily give an electron to molecular dioxygen [16]. Free radicals arise through the autoxidation catalyzed by metalloproteins, this mainly occurs within the mitochondria. Some experimental results proved that hydrogen can permeate

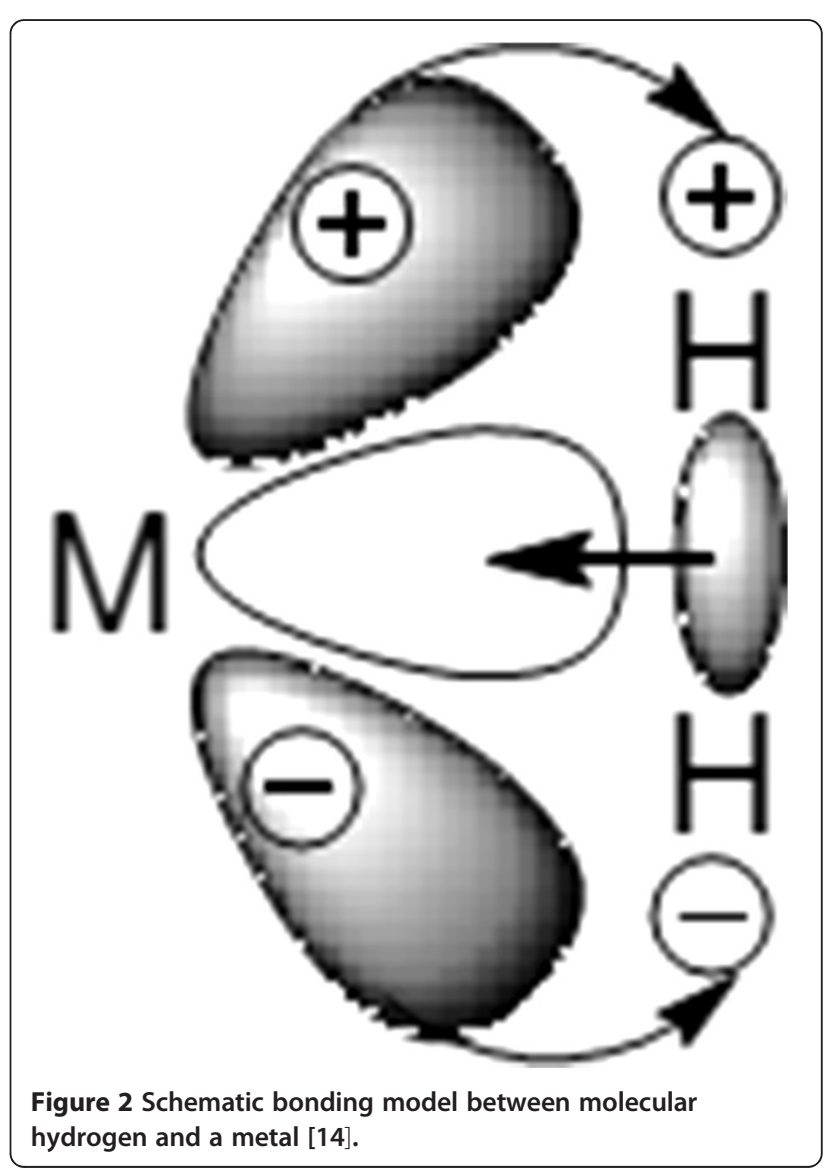



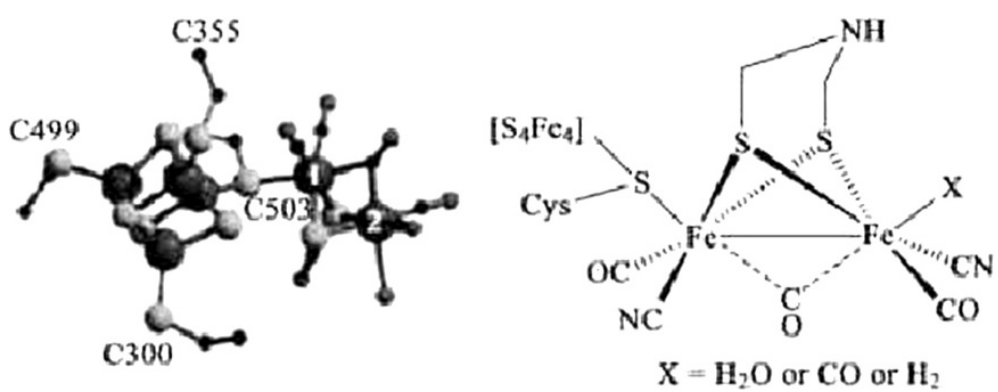

Figure 3 Stereo view of the $\mathrm{Cpl} \mathrm{H-cluster} \mathrm{and} \mathrm{coordinating} \mathrm{Cys} \mathrm{ligands} \mathrm{located} \mathrm{at} \mathrm{the} \mathrm{boundary} \mathrm{of} \mathrm{the} \mathrm{two} \mathrm{lobes} \mathrm{of} \mathrm{the} \mathrm{active} \mathrm{site}$ domain [15].

into mitochondria and prevent superoxide formation [17]. It indicates that $\mathrm{H}_{2}$ can affect the metabolization of ROS by way of superoxie formation. And it must have a big impact on the content of $\mathrm{H}_{2} \mathrm{O}_{2}$. Besides, free radical production can also happen in other cellular compartments, such as NADPH oxidase. ROS production can interfere with signal transduction pathways [18-20]. ROS, in particular $\mathrm{H}_{2} \mathrm{O}_{2}$, are indeed second messengers for many physiological stimuli, some stimuli have been proven to induce mitochondrial $\mathrm{H}_{2} \mathrm{O}_{2}$ release [21].

On the basis of the mentioned analysis, we evaluate that metal ions could be appropriate role sites for $\mathrm{H}_{2}$ molecules. We propose that hydrogen can permeate into mitochondria and concentrate at mitochondrial membrane to regulate activity of metalloproteins (complexesI, II,III) by $\mathrm{M}-\mathrm{H}_{2}$ interaction. The same may be true of NADPH oxidase. This could reduce the production of superoxide and prevent synthesis of the hydroxyl from the source. Hydrogen, on the one hand, maybe regulate the content of $\mathrm{H}_{2} \mathrm{O}_{2}$ by affecting the metabolization of ROS. And then it disturbs signaling pathway. On the other hand, hydrogen maybe directly influence signal transduction by regulating particular metalloproteins of signaling pathways. It may be the mechanism of its extensive biology effect.

\section{Conclusions}

We propose that metalloproteins may be ones of the target molecules of $\mathrm{H}_{2}$ action. Metal ions may be appropriate role sites for $\mathrm{H}_{2}$ molecules. And in this way can we explain

Table 1 Iron-sulphur proteins in cells

\begin{tabular}{ll}
\hline Function & Protein class \\
\hline Catalysis & Bacterial nitrate reductase, Formate dehydrogenase, \\
& Fumarate reductase, Glutamine PRPP amidotransferase, \\
& Hydrogenase, Methane monooxygenase, NADH: \\
& ubiquinone reductase, Phthalate dioxygenase reductase, \\
& Succinate dehydrogenase, Sulphite reductase, Xanthine \\
& dehydrogenase, Aconitase (TCA cycle) \\
Electron & Ferredoxins, Rieske proteins, Rubredoxins,NADH \\
transfer & Dehydrogenase, Succinate-CoQ Reductase,CoQ-cyt c \\
& Reductase (respiratory chain complexes) \\
\hline
\end{tabular}

its extensive biology effect. Although some details remain murky, the hypothesis pointed out a new direction for the continuation. It is a good inspiration to clarify the mechanism of the effect of hydrogen. We predict that hydrogen can affect many metalloproteins activities.Therefore, more studies will be necessary to test the hypothesis.

\section{Acknowledgment}

We wish to sincerely thank Xuejun Sun (Second Military Medical University, Shanghai, China) for advice about the manuscript.

\section{Funding}

There is no source of support in the form of grants.

\section{Author details}

${ }^{1}$ Gansu Key Lab of Crop Improvement \& Germplasm Enhancement, Gansu Provincial Key Laboratory of Aridland Crop Sciences, Gansu Agricultural University, Lanzhou 730070, China. ${ }^{2}$ Inner Mongolia University of Science and Technology, School of Material and Metallurgy, Baotou 014010, China.

${ }^{3}$ Gansu Agricultural University, Anning District, Lanzhou City, Gansu Province, China.

Received: 23 May 2012 Accepted: 23 May 2012

Published: 21 June 2012

\section{References}

1. Vaughan M: Oxidative modification of macromolecules minireview series. J Biol Chem 1997, 272:18513.

2. Hagen $T M$, Ingersoll RT, Lykkesfeldt J, Liu J, Wehr CM, Vinarsky V Bartholomew JC, Ames AB: (R)-alpha-lipoic acid-supplemented old rats have improved mitochondrial function, decreased oxidative damage, and increased metabolic rate. FASEB J 1999, 13:411-418.

3. Woo ES, Lazo JS: Nucleocytoplasmic functionality of metallothionein. Cancer Res 1997, 57:4236-4241.

4. Ohsawa I, Ishikawa M, Takahashi K, et al: Hydrogen acts as a therapeutic antioxidant by selectively reducing cytotoxic oxygen radicals. Nat Med 2007, 13:688-694.

5. Morel Y, Barouki R: Repression of gene expression by oxidative stress. Biochem J 1999, 342:481-496.

6. Wood KC, Gladwin MT: The hydrogen highway to reperfusion therapy. Nat Med 2007, 13:673-674.

7. Itoh T, Fujita Y, Ito M, et al: Molecular hydrogen suppresses FceRImediated signal transduction and prevents degranulation of mast cells. Biochem Biophys Res Commun 2009, 389:651-656.

8. Kubas GJ, Ryan RR, Swanson BI, Vergamini PJ, Wasserman HJ: J Am Chem Soc 1984, 106:451-452.

9. Darensbourg MY, Lyon EJ, Smee JJ: The bio-organometallic chemistry of active site iron in hydrogenases. Coord Chem Rev 2000, 219/221:533-561.

10. Marr AC, Spencer DJE, Schurder M: Structural mimics for the active site of [NiFe] hydrogenase. Coord Chem Rev 2001, 219/221:1055-1074.

11. Nicolet $Y$, de Lacey AL, Vernde $X$, et al: Crystallographic and FTIR Spectroscopic Evidence of Changes in Fe Coordination Upon Reduction 
of the Active Site of the Fe-Only Hydrogenase from Desulfovibrio desulfuricans. J Am Chem Soc 2001, 123:1596-1601.

12. Lawrence JD, Li HX, Rauchfuss TB, et al: Angew Chem Int Ed 2001, 40:1768-1771

13. Cowan JA: Inorganic Biochemistry: An Introduction. New York: VCH Publishers; 1993.

14. Martin HG: Prechtl. WiKu: Publisher; 2007

15. He Chengjiang WangMei, Li Minna, Sun Licheng: Advance in chemical mimic of fe-only hydrogenase. Progress in chemistry 2004, 16(2):250-255.

16. Kagan VE, Tyurina YY: Recycling and redox cycling of phenolic antioxidants. Ann N Y Acad Sci 1998, 854:425-434.

17. Sato $Y$, Kajiyama $S, A m a n o ~ A$, et al: Hydrogen-rich pure water prevents superoxide formation in brain slices of vitamin C-depleted SMP30/GNL knockout mice. Biochem Biophys Res Commun 2008, 375:346-350.

18. Finkel T: Oxygen radicals and signaling. Curr Opin Cell Biol 1998, 10:248-253.

19. Lander HM: An essential role for free radicals and derived species in signal transduction. FASEB J 1997, 11:118-124.

20. Suzuki YJ, Forman HJ, Sevanian A: Oxidants as stimulators of signal transduction. Free Radical Biol. Med 1997, 22:269-285.

21. Quillet-Mary A, Jaffrezou JP, Mansat V, Bordier C, Naval J, Laurent G: Implication of mitochondrial hydrogen peroxide generation in ceramideinduced apoptosis. J Biol Chem 1997, 272:21388-21395.

doi:10.1186/2045-9912-2-17

Cite this article as: Shi et al: A hypothesis on chemical mechanism of the effect of hydrogen. Medical Gas Research 2012 2:17.

\section{Submit your next manuscript to BioMed Central and take full advantage of:}

- Convenient online submission

- Thorough peer review

- No space constraints or color figure charges

- Immediate publication on acceptance

- Inclusion in PubMed, CAS, Scopus and Google Scholar

- Research which is freely available for redistribution 